\title{
Ability transmission, endogenous fertility, and educational subsidy
}

\author{
Kazumasa Oguro ${ }^{*}$, Hitotsubashi University \\ Takashi Oshio, Hitotsubashi University \\ Junichiro Takahata, Hitotsubashi University
}

\begin{abstract}
In this study, we attempt to investigate how educational subsidy, childcare allowance, and family allowance affect economic growth and income distribution, on the basis of simulation models which incorporate intergenerational ability transmission and endogenous fertility. The simulation results show that financial support for higher education can both increase economic growth and reduce income inequality, especially if the abilities of parent and child are closely correlated. In contrast with educational subsidy, raising childcare allowance or family allowance has limited impacts on growth and income inequality.
\end{abstract}

Keywords: Ability transmission; endogenous fertility; educational subsidy

\footnotetext{
*Corresponding author: Kazumasa Oguro, Institute of Economic Research, Hitotsubashi University, 2-1 Naka, Kunitachi, Tokyo, 186-8603, Japan. E-mail: oguro@ier.hit-u.ac.jp. The original version of this paper was presented at the Investigative Meeting of RIETI Discussion Paper on April 5, 2010. We are grateful for the helpful comments and discussions of Masayuki Morikawa, Daigo Nakata, Ayumu Tanaka, and the meeting participants. Any remaining errors are the responsibility of the authors. This paper is part of the academic project on Economic Analysis of Intergenerational Issues: Searching for Further Development, funded by the Grant-in-Aid for Specially Promoted Research from Japan's Ministry of Education, Culture, Sports, Science and Technology (grant number 22000001).
} 


\section{Introduction}

Household income, education, fertility, and individual ability are closely linked to each other, and their interactions likely affect economic growth and income distribution. In fact, it is widely known that poor parents tend to have more children and provide them with low education, while affluent parents tend to have fewer children and provide them with high education (see Becker and Tomes (1976) and Hanushek (1992)). In addition, differential fertility among households potentially affects economic growth, reflecting a negative correlation between fertility and education levels. Moreover, education may sustain or even widen income inequality with successive generations, because children born to rich parents can become even richer through higher education, while those born to poor parents cannot.

These dynamics, however, are likely to depend heavily on the degree of ability transmission from parents to children, as already pointed out by many preceding researches, beginning with a seminal paper by Becker and Tomes (1979). It may well be that income inequality keeps widening if ability is strongly transmitted between generations. If ability is randomly transmitted, by contrast, it would at least partially offset intergenerational transmission of income inequality. It is also of great interest to examine how the dynamics of economic growth and income distribution are affected by policy measures to financially support childcare or education, explicitly taking ability transmission into account.

There have been many studies, including Galor and Zhang (1997), which discuss the interactions among income inequality, differential fertility, and economic growth. Kremer and Chen (2002) empirically examined a correlation between income inequality and differential fertility, using cross-country data. They found that inequality 
tends to have a positive relationship with differential fertility. De la Croix and Doepke (2003) examined the relationship among economic inequality, differential fertility, and growth by using growth regression models. They found a significantly negative association between differential fertility and growth, and their regressions revealed that income inequality as measured by Gini coefficients does not affect growth, once differential fertility is included as an explanatory variable.

In addition, de la Croix and Doepke (2003) developed an overlapping generations (OLG) model with a channel from inequality to growth, showing that inequality affects growth through its effect on human capital and fertility. They showed that economies with less equitable income distribution raise differential fertility, decelerate human capital accumulation, and lower economic growth; they thereby highlighted the importance of income redistribution through tax and educational subsidy. Their studies, however, did not explore the dynamics of ability transmission from parents to children, which is most likely to affect education investment and income distribution.

The importance of ability transmission in human capital has been demonstrated in an analogical way, as well, as genetic versus environmental factors in biology, following Becker (1967). In this approach, ability corresponds to the genetic influences with which children are endowed by their parents, while parents' choice of child education corresponds to environmental factors for human capital. A return from human capital investment is determined largely by a combination of ability and education.

In addition, information about ability affects education: a child's higher ability increases parents' demand for education due to a higher rate of return from it. Using this approach, some recent studies focused on the relation between individual ability and human capital. For example, Han and Mulligan (2001) found that earnings 
mobility tends to be greater in economies with less variance in ability. It may well be that a lower correlation between parent and child abilities leads to a greater earnings mobility.

Along with these theoretical and empirical studies, there has been a growing number of researches on the impacts of educational policies on economic growth and income distribution, including Glomm and Ravikumar (1992), Iyigun (1999), Maoz and Moav (1999), Fender and Wang (2003), and Hanushek, Leung, and Yilmaz (2003) (2004). It is reasonable that efficiency and redistributive aspects of educational policies have been focused on, considering that education enhances human capital for society as a whole and, at the same time, causes income transfer across individuals through publicly financing its costs. The key limitation to these studies is, however, that they assume fertility to be exogenous, while it may well both affect and be affected by intergenerational ability transmission and income distribution among households.

Following on from these preceding studies and considering their limitations, we explore an OLG model that explicitly investigates all ability transmission, fertility difference, human capital, economic growth, and income distribution. Starting with the initial distribution of individual abilities, our model describes how individuals with different abilities choose education levels for their education and how their choices affect economic growth and income distribution through ability transmission. By utilizing this dynamic model, we examine how policy measures such as educational subsidy, childcare allowance, and family allowances affect economic growth and income distribution. The simulation results show that educational subsidy can both increase economic growth and reduce income inequality, especially if ability is fully transmitted from parents to children. In contrast with educational subsidy, raising childcare allowance or family allowance has limited impact on growth and inequality. 
The remainder of this paper is organized as follows. Section 2 presents a simple analysis for intuitive understanding. Section $\mathbf{3}$ establishes a main model for simulation analysis. Section 4 describes simulation results. Finally, Section 5 presents some concluding remarks.

\section{Simple analysis}

To make discussions intuitively understandable, we start with a very simple model, in which there exist only two generations: the parent generation (generation 0) and the child generation (generation 1). Each generation has two abilities, high ability, $x^{H}$, and low ability, $x^{L}\left(x^{L}<x^{H}\right)$. The numbers of individuals in the parent generation with high and low ability are set equal to 1 each, and the wages per ability of the high and low educated workers are denoted by $w^{H}$ and $w^{L}$, respectively. We assume unisexual reproduction and that the children born from the same parent all have the same ability. High-ability parents have high-ability children at the probability $p$ and low-ability ones at the probability 1- $p(0<p<1)$. Similarly, low-ability parents have high-ability children at the probability 1-p and low-ability ones at the probability $p$. The parameter, $p$, indicates the degree of ability transmission from parents to children. If $p=1$, the ability of the parent is fully transmitted to their children. If $p=0.5$, the ability is randomly transmitted.

Suppose further that (1) only children with rich parents and high ability can receive high education (in other words, high education requires both own high ability and high household income $)^{1} ;(2)$ income is determined by the product of ability and education, that is, $w^{i} x^{j}(i, j=L, H)$; and (3) as an initial condition, all parents with high (low)

\footnotetext{
1 This constraint will be relaxed in Section 3 .
} 
ability are high (low)-educated and, hence, rich (poor). We also assume that each parent has one child, meaning that this simple analysis does not discuss fertility.

In this model, there are two types of rich parents: those who have children with high ability $\left(x^{H}\right)$ and those who have children with low ability $\left(x^{L}\right)$. Rich parents who have high-ability children - the proportion of such parents is $p$-provide their children with high education. The number and income of their children are $p$ and $w^{H} x^{H}$, respectively. Rich parents who have low-ability children - the proportion of such parents is $1-p$ - provide their children with low education. The proportion and income of their children are $1-p$ and $w^{L} x^{L}$, respectively.

Similarly, there are two types of poor parents: those who have high-ability children and those who have low-ability children. The proportions of each type of parent are 1-p and $p$. Given that poor parents can provide their children with only low education, their children are two types: those who have high ability and are low-educated and those who have low ability and are low-educated. Their proportions and income are 1- $p, p$, and $w^{L} x^{H}, w^{L} x^{L}$, respectively.

Hence, the child generation consists of three types of children: (1) those who have high ability and are high-educated, (2) those who have high ability and are low-educated, and (3) those who have low ability and are low-educated. Their composition is as follows:

High-income children (with income $x^{H} w^{H}$ ): $\quad p$

Middle-income children (with income $x^{H} w^{L}$ ): 1-p

Low-income children (with income $\left.x^{L} w^{L}\right): \quad(1-p)+p=1$

If the government implements policy measures to financially support education for high-ability children born to poor parents-the proportion of such children is 
1- $p$ - these can receive high education. ${ }^{2}$ These children will obtain income $w^{L} x^{H}$, compared with $w^{H} x^{H}$ with no policy measures, As a result, the composition of the child generation's population changes to the following:

High-income children (with income $\left.x^{H} w^{H}\right): p+(1-p)=1$

Middle-income children (with income $x^{H} w^{L}$ ): 0

Low-income children (with income $\left.x^{L} w^{L}\right):(1-p)+p=1$.

To illustrate, suppose $x^{H}=1, x^{L}=0.5, w^{H}=2, w^{L}=1$. Then, before implementing policy measures, the mean and Gini coefficient of the child generation, denoted by $\mu_{1}$ and $G I N I_{1}$, respectively, are calculated as

$$
\mu_{1}=\frac{p x^{H} w^{H}+(1-p) x^{H} w^{L}+x^{L} w^{L}}{2}=\frac{2 p+(1-p)+0.5}{2}=0.75+\frac{p}{2}
$$

and

$$
\begin{aligned}
G I N I_{1} & =\frac{(1-p)\left(w^{L} x^{H}-w^{L} x^{L}\right)+p\left(w^{H} x^{H}-w^{L} x^{L}\right)+p(1-p)\left(w^{H} x^{H}-w^{L} x^{H}\right)}{2 p w^{H} x^{H}+2(1-p) w^{L} x^{H}+2 w^{L} x^{L}} \\
& =\frac{0.5(1-p)+1.5 p+p(1-p)}{4 p+2(1-p)+1}=\frac{0.5+2 p-p^{2}}{2 p+3} .
\end{aligned}
$$

With educational subsidy, they turn to $\mu_{1}{ }^{*}$ and $G I N I_{1}{ }^{*}$ such that

$$
\mu_{1}^{*}=\frac{x^{H} w^{H}+x^{L} w^{L}}{2}=\frac{2+0.5}{2}=1.25
$$

and

$$
G I N I_{1}^{*}=\frac{w^{H} x^{H}-w^{L} x^{L}}{2 w^{H} x^{H}+2 w^{L} x^{L}}=\frac{2-0.5}{4+1}=0.3
$$

Hence, we have $\mu_{1}{ }^{*}>\mu_{1}$ for all $p(0<p<1)$ and $G I N I_{1}{ }^{*}<G I N I_{1}$ as long as $p>0.4$. These results point to the possibility that the government can both increase economic growth and reduce income inequality, unless ability is reversely transmitted from the

\footnotetext{
${ }^{2}$ For simplicity we ignore taxes to finance these policy measures for the parent generation.
} 
parent to children. Financial support for education provides high-ability children born to poor parents with more chances to receive high education, which raises the average income and shifts the income distribution toward the higher end. ${ }^{3}$

However, endogenous fertility would make the analysis much more complex, because parents are likely to change the number of children when they receive financial support from the government. Hence, in the next section, we construct an OLG model that incorporates ability transmission and endogenous fertility; we also consider the budget constraint of the government that finances expenditures by taxation.

\section{The model}

\subsection{Individuals}

In this section, we construct an OLG model with the transmission of individual ability and endogenous fertility to examine the effect of educational subsidy and childcare and family allowances. Each generation lives for two periods: childhood and adulthood, and all decisions are made in the adult period of life. For simplicity, we assume unisexual reproduction and that all children born to the same parent share the same ability and are provided with the same level of education.

Individual ability, $x_{t}$, is distributed in the range between zero and one. The outcome of education choice depends on the child's ability. If the parent provides the child with low education $\left(e_{t+1}^{L}\right)$, the child obtains a low wage (per ability) $\left(w_{t+1}^{L}\right)$ regardless of his/her ability. If the parent provides the child with high education $\left(e_{t+1}^{H}\right)$, the child

\footnotetext{
${ }^{3}$ It should be noted, however, that this type of educational support cannot help low-ability individuals receive high education.
} 
obtains a high wage $\left(w_{t+1}^{H}\right)$ at the probability $x_{t+1}$ and a low wage $\left(w_{t+1}^{L}\right)$ at the probability of $1-x_{t+1}$, following de la Croix et al. (2003) and Hanushek et al. (2004). It should be noted here that high education does not guarantee a high wage and that high-ability children are more likely to benefit from high education than low-ability children.

The budget constraint for individuals with ability $x_{t}$ in generation $t$ who choose education of level $i$ for their children is expressed as

$$
n_{t+1}\left(\xi_{t}+e_{t+1}^{i}-\delta_{t}\right)+c_{t}=\left(1-\tau_{t}\right) k x_{t} w_{t}^{j}\left(1-\varsigma n_{t+1}\right)+m_{t} .
$$

Here, $\xi_{t}$ is the basic cost of childrearing; $\varsigma$ is the parameter of the opportunity cost of childbearing; $\delta_{t}$ is the child allowance; $\tau_{t}$ is the wage tax rate; $k$ is the aggregate productivity; and $m_{t}$ is the family allowance. The costs of high and low education, the basic cost of childrearing, and the child allowance are proportional to the average after-tax income, $\bar{W}_{t}^{A}$, while the family allowance is proportional to the average before-tax income, $\bar{W}_{t}^{B}$ :

$$
\begin{aligned}
& \xi_{t} \equiv \xi \bar{W}_{t}^{A}, \\
& \delta_{t} \equiv \delta \bar{W}_{t}^{A}, \\
& m_{t} \equiv m \bar{W}_{t}^{B}, \\
& e_{t+1}^{L}=e^{L} \bar{W}_{t}^{A}, \\
& e_{t+1}^{H} \equiv e^{H} \bar{W}_{t}^{A}-\theta_{t+1}=e^{H} \bar{W}_{t}^{A}-\theta\left(e^{H}-e^{L}\right) \bar{W}_{t}^{A}, \\
& \bar{W}_{t}^{A} \equiv\left(1-\tau_{t}\right) \frac{\int_{0}^{1} k x_{t} w_{t}^{H} N_{t}^{H}\left(x_{t}\right) d x_{t}+\int_{0}^{1} k x_{t} w_{t}^{L} N_{t}^{L}\left(x_{t}\right) d x_{t}}{\int_{0}^{1} N_{t}^{H}\left(x_{t}\right) d x_{t}+\int_{0}^{1} N_{t}^{L}\left(x_{t}\right) d x_{t}}+m_{t}, \\
& \bar{W}_{t}^{B} \equiv \frac{\int_{0}^{1} k x_{t} w_{t}^{H} N_{t}^{H}\left(x_{t}\right) d x_{t}+\int_{0}^{1} k x_{t} w_{t}^{L} N_{t}^{L}\left(x_{t}\right) d x_{t}}{\int_{0}^{1} N_{t}^{H}\left(x_{t}\right) d x_{t}+\int_{0}^{1} N_{t}^{L}\left(x_{t}\right) d x_{t}},
\end{aligned}
$$

where $N_{t}^{H}\left(x_{t}\right)$ and $N_{t}^{L}\left(x_{t}\right)$ represent the numbers of individuals with ability $x_{t}$ and high wages $\left(w_{t}^{H}\right)$ and low wages $\left(w_{t}^{L}\right)$, respectively, and $\theta, \xi, \delta$ and $m$ are positive parameters. 
As for education costs, we assume that the government gives subsidies $\theta_{t+1}$ to high education (but not to low education), given positive parameters $e^{L}$ and $e^{H}\left(>e^{L}\right)$. We discuss the dynamics of the population, $N_{t}^{H}\left(x_{t}\right)$ and $N_{t}^{L}\left(x_{t}\right)$, in Section 3.2.

Each individual in generation $t$ cares about his or her own consumption, $c_{t}$; the number of children, $n_{t+1}$; and the quality of children to maximize the utility. The quality of children is evaluated by the wage, $w_{t+1}^{i}$, which reflects human capital obtained by education. More specifically, if individuals with ability $x_{t}$ and the wage $\mathrm{w}_{t}^{i}$ provide their children with low education, $e_{t+1}^{L}$, then their expected utility is described as

$$
\begin{aligned}
& E\left(U_{t}\right)=U_{t}=\alpha \log \left(w_{t+1}^{L}\right)+\beta \log \left(n_{t+1}\left(e_{t+1}^{L}\right)\right)+\gamma \log \left(c_{t}\left(e_{t+1}^{L}\right)\right), \\
& 0<\alpha, \beta, \gamma<1, \alpha+\beta+\gamma=1
\end{aligned}
$$

considering that the children obtain a low wage, $w_{t+1}^{L}$, regardless of their ability if they are provided with low education.

It is reasonable to suppose that individuals with higher income are more likely to prefer child quality to child quantity; that is, they are more inclined to have fewer children with more education. In this model, the cost of education is fixed and proportional to the average before-tax wage among the child generation (see equations (2) and (3)), meaning that education is more expensive for a poorer parent. In contrast, the opportunity cost of childrearing is proportional to the parent's after-tax wage (see equation (1)). Hence, individuals with higher income may well have fewer children with higher education, all other things being equal.

If an individual chooses high education for his/her children, then that individual's expected utility is expressed as

$$
E\left(U_{t}\right)=\alpha x_{t+1} \log \left(w_{t+1}^{H}\right)+\alpha\left(1-x_{t+1}\right) \log \left(w_{t+1}^{L}\right)+\beta \log \left(n_{t+1}\left(e_{t+1}^{H}\right)\right)+\gamma \log \left(c_{t}\left(e_{t+1}^{H}\right)\right),
$$

as the children obtain a high wage, $w_{t+1}^{H}$, at the probability $x_{t+1}$ and a low wage, $w_{t+1}^{L}$, 
at the probability $1-x_{t+1}$.

Each individual determines the level of education for the children to maximize the expected utility, which is given by (9) or (10), under the budget constraint (1). If an individual chooses low education, the first order conditions for utility maximization are

$$
\begin{aligned}
& n_{t+1}\left(x_{t}, w_{t}^{i}, e_{t+1}^{L}\right)=\frac{\beta\left(\left(1-\tau_{t}\right) k x_{t} w_{t}^{i}+m_{t}\right)}{\xi_{t}+e_{t+1}^{L}-\delta_{t}+\left(1-\tau_{t}\right) k x_{t} w_{t}^{i} \varsigma}, \\
& c_{t}\left(x_{t}, w_{t}^{i}, e_{t+1}^{L}\right)=\gamma\left(\left(1-\tau_{t}\right) k x_{t} w_{t}^{i}+m_{t}\right) .
\end{aligned}
$$

Thus, the indirect utility function, $U_{t}\left(x_{t}, w_{t}^{i}, e_{t+1}^{L}\right)$, is calculated as

$$
U_{t}\left(x_{t}, w_{t}^{i}, e_{t+1}^{L}\right)=\log \left[\left(w_{t+1}^{L}\right)^{\alpha} \beta^{\beta} \gamma^{\gamma} \frac{\left(\left(1-\tau_{t}\right) k x_{t} w_{t}^{i}+m_{t}\right)^{\beta+\gamma}}{\left(\xi_{t}+e_{t+1}^{L}-\delta_{t}+\left(1-\tau_{t}\right) k x_{t} w_{t}^{i} \varsigma\right)^{\beta}}\right] .
$$

If an individual chooses high education for the children, the first order conditions for utility maximization are given as

$$
\begin{aligned}
& c_{t}\left(x_{t}, w_{t}^{i}, e_{t+1}^{H}\right)=\gamma\left(\left(1-\tau_{t}\right) k x_{t} w_{t}^{i}+m_{t}\right), \\
& n_{t+1}\left(x_{t}, w_{t}^{i}, e_{t+1}^{H}\right)=\frac{\beta\left(\left(1-\tau_{t}\right) k x_{t} w_{t}^{i}+m_{t}\right)}{\xi_{t}+e_{t+1}^{H}-\delta_{t}+\left(1-\tau_{t}\right) k x_{t} w_{t}^{i} \zeta} .
\end{aligned}
$$

Letting $U_{t}^{H}\left(x_{t}, w_{t}^{i}, e_{t+1}^{H}\right)$ and $U_{t}^{L}\left(x_{t}, w_{t}^{i}, e_{t+1}^{H}\right)$ denote the indirect utility functions for the cases where the children obtain high and low wages, respectively, we have the expected utility of an individual who chooses high education for his/her children:

$$
E\left(U_{t}\left(x_{t}, w_{t}^{i}, e_{t+1}^{H}\right)\right)=x_{t+1} U_{t}^{H}\left(x_{t}, w_{t}^{i}, e_{t+1}^{H}\right)+\left(1-x_{t+1}\right) U_{t}^{L}\left(x_{t}, w_{t}^{i}, e_{t+1}^{H}\right)
$$

where

$$
U_{t}^{j}\left(x_{t}, w_{t}^{i}, e_{t+1}^{H}\right)=\log \left[\left(w_{t+1}^{j}\right)^{\alpha} \beta^{\beta} \gamma^{\gamma} \frac{\left(\left(1-\tau_{t}\right) k x_{t} w_{t}^{i}+m_{t}\right)^{\beta+\gamma}}{\left(\xi_{t}+e_{t+1}^{H}-\delta_{t}+\left(1-\tau_{t}\right) k x_{t} w_{t}^{i} \varsigma\right)^{\beta}}\right], j=H, L .
$$

In deciding the level of education, an individual compares expected utilities obtained from high and low education. The condition under which the individual chooses high education for his/her children is expressed as 


$$
E\left(U_{t}\left(x_{t}, w_{t}^{i}, e_{t+1}^{H}\right)\right)>U_{t}\left(x_{t}, w_{t}^{i}, e_{t+1}^{L}\right)
$$

which is rewritten as

$$
x_{t+1}>\bar{x}_{t+1}\left(x_{t}, w_{t}^{i}\right) \equiv \frac{\beta \log \left(\frac{\xi_{t}+e_{t+1}^{H}-\delta_{t}+\left(1-\tau_{t}\right) k x_{t} w_{t}^{i} \varsigma}{\xi_{t}+e_{t+1}^{L}-\delta_{t}+\left(1-\tau_{t}\right) k x_{t} w_{t}^{i} \varsigma}\right)}{\alpha \log \left(w_{t+1}^{H} / w_{t+1}^{L}\right)}
$$

using equations (13)-(15). This condition indicates that an individual is likely to choose high education if the child's ability is observed to be high enough. Moreover, simple calculations show $\partial \bar{x}_{t+1} / \partial w_{t}^{i}<0$, indicating that children with high ability likely fail to receive high education if the parent is poor.

\subsection{Ability transmission and income distribution}

Following Hanushek et al. (2004), we assume the mechanism of ability transmission from the parent to the child:

$$
x_{t+1} \equiv g\left(x_{t}\right)=\mathrm{mi}\left[\mathrm{mm} \text { a }\left(\sigma_{1}+\sigma_{2} x_{t}+\sigma_{3} u_{t}, 0\right), 1\right]
$$

where $u_{t}$ is a white noise that obeys the standard normal distribution at each period. This transmission mechanism keeps ability within the range of $[0,1]$ in any generation. If $\left(\sigma_{1}\right.$, $\left.\sigma_{2}, \sigma_{3}\right)=(0,1,0)$, for instance, the parent's ability is fully transmitted to the children. In the case of $\left(\sigma_{1}, \sigma_{2}, \sigma_{3}\right)=(-0.25,0.5,0.25)$, ability is only partly transmitted and has a downtrend with random fluctuations.

By combining an individual's utility maximization described in the previous section and the ability transmission mechanism given by equation (20), we derive the dynamics of ability and income distribution. Let $N_{t}^{H}\left(x_{t}\right)$ and $N_{t}^{L}\left(x_{t}\right)$ denote the numbers of individuals in generation $t$ who have ability $x_{t}$ and obtain the high and low wages $w_{t}^{H}$, $w_{t}{ }^{L}$, respectively. Each of them transmits his/her ability to his/her children through the mechanism expressed as equation (20). Due to the white noise, $u_{t}$, even individuals with 
the same ability may have children with different abilities.

Now, suppose that there are $\Omega_{t}^{H}\left(x_{t+1}, x_{t}\right)$ individuals in generation $t$ who have ability $x_{t}$, a high wage $w_{t}^{H}$, and children with ability $x_{t+1}$. In the same way, let $\Omega_{t}^{L}\left(x_{t+1}, x_{t}\right)$ denote the number of individuals in generation $t$ who have ability $x$, a low wage $w_{t}^{L}$, and children with ability $x_{t+1}$. We have $0 \leq \Omega_{t}^{H}\left(x_{t+1}, x_{t}\right) \leq N_{t}^{H}\left(x_{t}\right)$ and $0 \leq \Omega_{t}^{L}\left(x_{t+1}, x_{t}\right) \leq N_{t}^{L}\left(x_{t}\right)$. Then, we denote the number of individuals in generation $t+1$ who have ability $x_{t+1}$ and obtain a high wage $w_{t}^{H}$ as

$$
\begin{aligned}
N_{t+1}^{H}\left(x_{t+1}\right) & =x_{t+1} \int_{0}^{1} \theta\left(x_{t+1}-\bar{x}_{t+1}\left(x_{t}, w_{t}^{H}\right)\right) n_{t+1}\left(x_{t}, w_{t}^{H}, e_{t+1}^{H}\right) \Omega_{t}^{H}\left(x_{t+1}, x_{t}\right) d x_{t} \\
& +x_{t+1} \int_{0}^{1} \theta\left(x_{t+1}-\bar{x}_{t+1}\left(x_{t}, w_{t}^{L}\right)\right) n_{t+1}\left(x_{t}, w_{t}^{L}, e_{t+1}^{H}\right) \Omega_{t}^{L}\left(x_{t+1}, x_{t}\right) d x_{t}
\end{aligned}
$$

where $\theta(q)$ is a Heaviside step function (and $\theta=1$ if $q>0 ;=0$ if $q \leq 0$ ). The first term of the equation (21) represents the number of generation $t+1$ who have ability $x_{t+1}$, receive high education $\left(e_{t+1}^{H}\right)$, and correspondingly obtain high wages $\left(w_{t+1}^{H}\right)$, among those who have parents with high wages $\left(w_{t}{ }^{H}\right) .{ }^{4}$ Similarly, the second term indicates the number of individuals in generation $t+1$ who have ability $x_{t+1}$, receive high education, and correspondingly obtain high wages among those who have parents with low wages $\left(w_{t}^{L}\right)$.

In the same way, we derive the number of individuals in generation $t+1$ with ability $x_{t+1}$ and low wage $w_{t}^{L}, N_{t+1}^{L}\left(x_{t+1}\right)$ as

\footnotetext{
${ }^{4}$ The reason is as follows: $n_{t+1}\left(x_{t}, w_{t}^{H}, e^{H}{ }_{t+1}\right) \Omega^{H}\left(x_{t+1}, x_{t}\right)$ indicates the total number of individuals in generation $t+1$ with ability $x_{t+1}$ born to the parents with high wages $w_{t}^{H}$. Among these individuals, only those with $x_{t+1} \geq \bar{x}_{t+1}\left(x_{t}\right.$, $w_{t}^{H}$ ) can receive high education. Integrating them with respect to ability $x_{t}$ from zero to one yields the total number of individuals in generation $t$ who receive high education. Finally, $x_{t+1} \times 100 \%$ of them obtain high wages.
} 


$$
\begin{aligned}
N_{t+1}^{L}\left(x_{t+1}\right) & =\left(1-x_{t+1}\right) \int_{0}^{1} \theta\left(x_{t+1}-\bar{x}_{t+1}\left(x_{t}, w_{t}^{H}\right)\right) n_{t+1}\left(x_{t}, w_{t}^{H}, e_{t+1}^{H}\right) \Omega_{t}^{H}\left(x_{t+1}, x_{t}\right) d x_{t} \\
& +\int_{0}^{1} \theta\left(\bar{x}_{t+1}\left(x_{t}, w_{t}^{H}\right)-x_{t+1}\right) n_{t+1}\left(x_{t}, w_{t}^{H}, e_{t+1}^{L}\right) \Omega_{t}^{H}\left(x_{t+1}, x_{t}\right) d x_{t} \\
& +\left(1-x_{t+1}\right) \int_{0}^{1} \theta\left(x_{t+1}-\bar{x}_{t+1}\left(x_{t}, w_{t}^{L}\right)\right) n_{t+1}\left(x_{t}, w_{t}^{L}, e_{t+1}^{H}\right) \Omega_{t}^{L}\left(x_{t+1}, x_{t}\right) d x_{t} \\
& +\int_{0}^{1} \theta\left(\bar{x}_{t+1}\left(x_{t}, w_{t}^{L}\right)-x_{t+1}\right) n_{t+1}\left(x_{t}, w_{t}^{L}, e_{t+1}^{L}\right) \Omega_{t}^{L}\left(x_{t+1}, x_{t}\right) d x_{t}
\end{aligned}
$$

The first term of the right-hand side of equation (22) indicates the number of individuals who receive high education but fail to obtain high wages among those who have parents with high wages $\left(w_{t}^{H}\right)$. The second term indicates the number of individuals who receive low education and hence obtain low wages in the same group. The third and fourth terms correspond to the first and second terms, respectively, among those who have parents with a low wage $\left(w_{t}^{L}\right)$.

Based on the dynamics of (21) and (22), the total number of individuals in generation $t$ with ability $x_{t}, N_{t}\left(x_{t}\right)$, is given as

$$
N_{t}\left(x_{t}\right)=N_{t}^{H}\left(x_{t}\right)+N_{t}^{L}\left(x_{t}\right)
$$

and the total population in generation $t, N_{t}$, is calculated by

$$
N_{t}=\int_{0}^{1} N_{t}\left(x_{t}\right) d x_{t}=\int_{0}^{1} N_{t}^{H}\left(x_{t}\right) d x_{t}+\int_{0}^{1} N_{t}^{L}\left(x_{t}\right) d x_{t},
$$

and the density function of ability in generation $t, f_{t}\left(x_{t}\right)$, is expressed as

$$
f_{t}\left(x_{t}\right)=\frac{N_{t}^{H}\left(x_{t}\right)+N_{t}^{L}\left(x_{t}\right)}{N_{t}}
$$

\subsection{Production and government}

The model is completed by introducing the production function and the government's budget constraint. We assume a CES production function:

$$
Y_{t}=A\left(\varepsilon\left(L_{t}^{H}\right)^{\rho}+(1-\varepsilon)\left(L_{t}^{L}\right)^{\rho}\right)^{1 / \rho}, A, \rho, \varepsilon>0
$$


where

$$
L_{t}^{j} \equiv \int_{0}^{1} k x_{t} N_{t}^{j}\left(x_{t}\right) d x_{t}, \quad j=H, L .
$$

Here, $L_{t}{ }^{H}$ and $L_{t}{ }^{L}$ are the total efficiency units of high- and low-wage labor, respectively, in generation $t$. In a competitive labor market, the wage is equal to the marginal product of each labor:

$$
\begin{aligned}
& w_{t}^{H}=A \varepsilon\left(L_{t}^{H}\right)^{\rho-1}\left(\varepsilon\left(L_{t}^{H}\right)^{\rho}+(1-\varepsilon)\left(L_{t}^{L}\right)^{\rho}\right)^{1 / \rho-1} \\
& w_{t}^{L}=A(1-\varepsilon)\left(L_{t}^{L}\right)^{\rho-1}\left(\varepsilon\left(L_{t}^{H}\right)^{\rho}+(1-\varepsilon)\left(L_{t}^{L}\right)^{\rho}\right)^{1 / \rho-1}
\end{aligned}
$$

Meanwhile, the government collects its revenue solely by taxes, and its budget constraint is expressed as

$$
T_{t}=G_{t}^{C O N}+G_{t}^{E D U}+G_{t}^{C A}+G_{t}^{F A}
$$

where $T_{t}, G_{t}^{C O N}, G_{t}^{E D U}, G_{t}^{C A}$, and $G_{t}^{F A}$ are the tax revenue and government's total expenditures on consumption, educational subsidy, childcare allowance, and family allowance, respectively. They are defined as

$$
\begin{aligned}
& T_{t} \equiv \tau_{t} Y_{t}, \\
& G_{t}^{C O N} \equiv c Y_{t}, c>0 \\
& G_{t}^{E D U} \equiv \theta_{\mathrm{t}+1} N^{H}{ }_{t+1}, \\
& G_{t}^{C A} \equiv \delta_{t} N_{t+1}, \\
& G_{t}^{F A} \equiv m_{t} N_{t} .
\end{aligned}
$$

\section{Simulation}

\subsection{Parameters, initial conditions, and scenarios}

The dynamics of our model are determined by equations (1) to (34), along with the given values of the parameters and the initial conditions. In simulations, we assume static expectations for wages; in other words, individuals expect their children's wages 
to be the same as their own $\left(w_{t+1}^{H}=w_{t}^{H}, w_{t+1}^{L}=w_{t}^{L}\right.$ in equations (9), (10), (13), (17) and (19)). The Appendix table explains how we determined the parameter values, most of which roughly correspond to the actual data in Japan or those used in the preceding studies.

The model starts with generation 1 , which consists of 100,000,000 individuals each for high- and low-wage groups. For both groups, we assume that individual ability is distributed normally with the mean 0.5 and the standard deviation 0.25 , and remove those with the ability below 0 or above 1 (whose proportion is about $4.6 \%$ of the population normally distributed with no truncation). We then randomly assign this normally distributed ability to each of 100,000,000 individuals in generation 1 , and let each individual make decisions about the number and education level of the children on the basis of the children's ability. Some children receive high education and high wages, while others do not, resulting in different distributions of ability and income from those of their parents. Then, the children, or individuals in generation 2 , make the same decisions as their parents. We repeat the same process until generation 10, taking into account intergenerational ability transmission. Furthermore, we repeat this simulation a hundred times to take the averages of simulation results in each generation. We will report these averages in what follows ${ }^{5}$.

We consider a combination of three cases (with different assumptions about ability transmission) and four policy scenarios to assess the dynamic and long-run policy impacts on the ability and wage distributions, population size, per capita GDP, and income inequality measured by the Gini coefficient. For ability transmission, we consider three cases that are featured by a set of three parameters $\left(\sigma_{1}, \sigma_{2}, \sigma_{3}\right)$ in equation

\footnotetext{
${ }^{5}$ All simulation results with their standard deviations and 95\% confidence intervals are available from the authors upon request.
} 
(7):

Case 1: $\left(\sigma_{1}, \sigma_{2}, \sigma_{3}\right)=(0,1,0)$,

Case 2: $\left(\sigma_{1}, \sigma_{2}, \sigma_{3}\right)=(0.125,0.75,0.1)$,

Case 3: $\left(\sigma_{1}, \sigma_{2}, \sigma_{3}\right)=(0.25,0.5,0.1)$.

In Case 1, ability is fully transmitted from parents to children without any disturbances, and its initial distribution is completely preserved in each consecutive generation. In Cases 2 and 3, ability is partially transmitted with the mean preserved at 0.5 in the steady state and some random disturbances. In these cases, ability becomes more concentrated around the mean-and at a faster pace in Case 3 than in Case 2-in successive generations.

In each case, we analyze the effects of three policy measures, which are expressed as a set of three policy parameters $(\theta, \delta, m)$ :

Baseline: $(\theta, \delta, \quad m)=(0,0.0225,0.2)$,

Educational subsidy: $(\theta, \delta, m)=(0.5,0.0225,0.2)$,

Childcare allowance: $(\theta, \delta, m)=(0,0.0225+\Delta \delta, 0.2)$,

Family allowance: $(\theta, \delta, m)=(0,0.0225,0.2+\Delta m)$.

We suppose that the government implements one of the three policy measures. For educational subsidy, the government subsidizes $50 \%$ of the difference in the costs of high and low education. For childcare allowance and family allowance, the government raises them from their baseline levels of 0.00225 and 0.2 , respectively. To compare their effects consistently, we adjust the childcare and family allowances to make the income tax rate, $\tau_{t}$, the same across the three policies in each generation. More specifically, we first calculate the tax rate for educational subsidy with $\theta=0.5$, and then adjust the parameters $\delta$ and $m$ (that is, calculate $\Delta \delta$ and $\Delta m$ ) to make the income tax rates for childcare and family allowances equal to that for educational 
subsidy in each generation.

$<$ Insert Table 1 about here. $>>$

Table 1 summarizes the evolutions of policy parameters $(\theta, \delta$, and $m)$ and income tax rates $(\tau)$ in generations 1,5 , and 10 for the baseline and the three policy scenarios in three cases of ability transmission. The top panel shows the results in Case 1 with full ability transmission and no disturbances. The baseline case shows that the tax rate remains slightly above 0.24 till generation 10 . To implement the educational subsidy $(\theta$ $=0.5$ ), the government needs to raise the tax rate to slightly above 0.25 . It can raise childcare and family allowances to around 0.033 (from 0.025 ) and 0.21 (from 0.2), respectively, with the income tax rate fixed at the stated level in the case of educational subsidy in each generation. The middle and bottom panels summarize the results in Cases 2 and 3. In comparison with Case 1, the government requires slightly higher tax rates to finance the three policy measures.

\section{$<<$ Insert Figure 1 about here. $>>$}

\subsection{Ability distribution}

Figure 1 depicts how the distribution of ability, which obeys a normal distribution with a mean of 0.5 and a standard deviation of 0.25 in generation 1 , turns out in generations 5 and 10 in the baseline and three policy scenarios, on the basis of three assumptions about ability transmission. ${ }^{6}$

\footnotetext{
6 The density of ability distribution in Figure 1 is expressed as $f_{5}\left(x_{5}\right)$ and $f_{10}\left(x_{10}\right)$ given by equation (25) with $t=5$
} and 10 . 
The top two panels of Figure 1 depict the results in Case 1 with full ability transmission with no disturbances. In generation 5, all four policy scenarios keep the ability distributions close to the normal distribution; however, the ability distribution has two cutoff points - around 0.3 and 0.45 . As the generation reaches the tenth, these discontinuities become clearer. As the ability rises to around 0.3 from zero, the density of individuals increases more than what the normal distribution would suggest. At around 0.3 , it drops sharply and resumes increasing and has the third cutoff point at around 0.45 . Beyond it, the ability distribution looks closer to what the normal distribution would suggest and has no discontinuities.

These changes in the ability distribution suggest that full or strong ability transition across generations, combined with financial constraints for education, is likely to increase the proportion of lower-than-average-ability individuals. This is a reasonable result, because low-ability individuals tend to be poor and face high thresholds for providing their children with high education (see equation (19)). They tend to choose a combination of a large number of children and a low level of education, leading to an increase in low-ability individuals in the subsequent generation. This adjustment continues in successive generations. Two things should be noted, however. First, the proportion of extremely low-ability individuals tends to stay low, because they are too poor to have even a small number of children. Second, there are a couple of discontinuities in the ability distribution, reflecting thresholds for choosing high education for children as discussed in Section 4.3.

Figure 1 compares the impacts of the three policy measures on the ability distribution as well. In contrast with the baseline and childcare and family allowances, educational subsidy moves the ability distribution closer to the normal distribution. It also reduces the proportion of low-ability individuals and raises the proportion of 
high-ability individuals. There are no substantial differences among the baseline and childcare and family allowances. These results indicate that only an educational subsidy affects the ability distribution by shifting it toward the higher end. Unlike childcare and family allowances, educational subsidy directly enhances the incentives to provide children with high education, which prevents income distribution from shifting toward the lower end. However, the top panels of Figure 1 suggest that the impact of educational subsidy on the ability distribution is limited even up to the tenth generation.

The middle and bottom panels of Figure 1 show the results in Cases 2 and 3, corresponding to strong and weak ability transmission, respectively. Unlike in Case 1, the ability distribution is close to the normal distribution in all of the baseline and three policy cases and it has no discontinuities. The ability distribution is dispersed in generation 5 in both Cases 2 and 3, but it converges to the normal distribution in generation 10 for all of the baseline and three policy scenarios. We also find that the ability distribution concentrates around 0.5 in Case 3 more than in Case 2, a reasonable result given a weak degree of ability transmission in Case 3.

In all, Figure 1 suggests that ability distribution is virtually insensitive to any policy measures if the ability transmission is not fully or very strongly transmitted. If the ability is fully or very strongly transmitted, only educational subsidy can prevent income distribution from shifting toward the lower end, while its impact is limited in the short run. However, it does not mean that our policy measures do not affect income distribution, because income is determined not only by ability but also wages. Hence, the next task is to examine how the three policy measures affect wage distribution. All three policies provide individuals with financial support to give their children high education. 


\section{$<<$ Insert Figure 2 about here. $>>$}

\subsection{Wage distribution}

Figure 2 presents the proportion of low-wage individuals (those who cannot receive high education) among those with the same ability but whose cases represent different degrees of ability transmission. The top two panels show the results in Case 1 with full ability transmission and no disturbances. As shown, there are no substantial differences among the baseline and childcare and family allowances, while educational subsidy provides quite different results from the other three policy scenarios.

In the baseline and childcare and family allowances, there are three groups of individuals. The first group, located at the top-left, consists of those with ability lower than around 0.42 . All of them obtain low wages. The second group, located at the bottom-right, consists of those with ability higher than around 0.45 . For them, the proportion of low-wage individuals falls linearly as ability rises above that level. Third, there is a small group of individuals that lie between the two groups; their ability is somewhere between 0.42 and 0.45 , and there is a negative correlation between ability and the proportion of low-wage individuals.

The discontinuous relationships between ability and the proportion of low-wage individuals in Case 1 are explained as follows. As seen in equation (19), generation $t$ has two thresholds for providing children with high education, $\tilde{x}_{t+1}^{H}$ and $\tilde{x}_{t+1}^{L}$ $\left(\tilde{x}_{t+1}^{H}<\tilde{x}_{t+1}^{L}\right)$, such that $\tilde{x}_{t+1}^{H}=\bar{x}_{t+1}\left(x_{t}, w_{t}^{H}\right)$ and $\tilde{x}_{t+1}^{L}=\bar{x}_{t+1}\left(x_{t}, w_{t}^{L}\right)$, where $\bar{x}_{t+1}\left(x_{t}, w_{t}^{H}\right)$

and $\bar{x}_{t+1}\left(x_{t}, w_{t}^{L}\right)$ correspond to the right-hand side of equation (19). That is, $\tilde{x}_{t+1}^{H}$ is the threshold for low-high wage individuals to choose high education for their children, and $\tilde{x}_{t+1}^{L}$ is that for low-wage individuals. Those with ability lower than $\tilde{x}_{t+1}^{H}$ receive 
low education and obtain low wages, regardless of their parents' wage levels. Those with ability higher than $\tilde{x}_{t+1}^{L}$ receive high education and $\left(1-x_{t+1}\right)$ of them obtain low wages regardless of their parents' wage levels. For those with ability between $\tilde{x}_{t+1}^{H}$ and $\tilde{x}_{t+1}^{L}$, all of them receive low education and obtain low wages if they are born from poor parents, while $\left(1-x_{t+1}\right)$ of them receive high education and obtain high wages if they are born from rich parents.

As seen on the left chart in the top panel, childcare and family allowances have virtually no impact on the wage distribution, because neither of them has much effect on the threshold for the choice of education (see equation (19)). By contrast, educational subsidy lowers the threshold for high education and correspondingly gives low-ability individuals more chances to receive high education. As a result, children with ability between around 0.3 and 0.45 are then able to receive high education and some of them succeed in obtaining high wages.

The right chart in the top panel illustrates what happens in generation 10 . We observe some differences in policy impacts from generation 5. Childcare and family allowances succeed in engendering some shifts from the top-left group (of low-wage individuals) to the middle one and from the middle group to the bottom-right one (of high-wage individuals), with some leftward shifts of two discontinuous points. This indicates that these two policy measures shift the wage distribution toward the higher end. As in generation 5, however, educational subsidy most substantially affects the wage distribution.

The middle and bottom panels present the results in Cases 2 and 3, which assume a partial ability transmission and disturbances. Individuals with very low ability can obtain only low wages, while the proportion of low-wage individuals declines as ability rises above a certain level and there is no discontinuity, unlike in Case 1 . We 
also observe that only educational subsidy can substantially reduce the proportion of low-wage individuals among those with low ability.

In all, Figure 2 indicates that only educational subsidy has a substantial impact on the wage distribution. It reduces the threshold for low-wage individuals to provide their children with high education, leading to a reduction in the proportion of low-ability individuals in society as a whole. Unlike the case of the ability distribution, educational subsidy shifts the wage distribution to the higher end even if ability is not fully transmitted from parents to children.

$<$ Insert Table 2 about here. $>>$

\subsection{Population size, per capita GDP, and income inequality}

Finally, we discuss the impacts of each policy on the population size and macro economy, which are summarized in Table 2. The top panel shows the impact on total population, where its initial size is normalized as 100. In all cases, total population decreases with each new generation, although the decrease is entirely due to the assumed parameters and will not necessarily occur. In all cases, we find that childcare allowance is most effective in expanding total population, a reasonable result considering that only childcare allowance directly reduces the cost of childrearing. The impact on the population size increases as the degree of ability transmission weakens, but the relative performance of the three policy measures remains unchanged.

The middle panel summarizes the impact on per capita GDP. Before assessing the policy impacts, we notice that per capita GDP tends to decline in Case 1, and to a lesser extent, Case 2, but remains almost unchanged in Case 3 in the baseline. This suggests that stronger ability transmission by itself tends to subdue economic growth, 
as strong ability transmission tends to increase the proportion of low-wage individuals, as seen from Figure 2 .

More importantly, we find that educational subsidy is the only policy measure to enhance per capita GDP. This is consistent with the results in Figures 1 and 2, which show that only educational subsidy can both shift the ability distribution toward the higher end and reduce the proportion of low-wage individuals among those with low ability.

However, educational subsidy becomes less effective in raising per capita GDP as ability transmission weakens. This is explained by two factors. As ability transmission weakens, the ability distribution becomes less affected by educational subsidy (as seen in Figure 1), and it becomes more concentrated on the average ability, reducing the impact of educational subsidy on wages, which works only for low-ability individuals (as seen in Figure 2). We also find that enhancing childcare allowance or family allowance reduces per capita GDP, although their impacts decline as ability transmission becomes weaker. These policies do not raise the average level of ability nor reduce the proportion of low-wage individuals, confirming the welfare loss due to additional taxation and transfer.

Finally, the bottom panel compares the evolutions of the Gini coefficients of household income. In the baseline, we notice that the Gini coefficient rises in succeeding generations in Case 1 while it declines in Cases 2 and 3. This confirms that stronger ability transmission tends to widen income inequality through unequal opportunities for education in successive generations. Comparing the three policy measures, we find that Policy 1 is most effective in preventing income inequality from widening (in Case 1) or reducing it (in Cases 2 and 3), because it provides economically disadvantaged children with more chances to receive high education. 
Judging by the results from Table 3 , we can conclude that educational subsidy is a more desirable policy measure than enhancing childcare allowance or family allowance in terms of both efficiency and equity, in that it can both raise economic growth and reduce income inequality most effectively, especially if ability is strongly transmitted between generations. In addition, by comparing Figures 1 and 2, we can argue that educational subsidy affects economic growth and income distribution largely through its impact on the wage distribution rather than on the ability distribution, especially if ability is not fully transmitted from parents to children.

\section{Concluding remarks}

In this study, we have investigated how educational subsidy, childcare allowance, and family allowance affect economic growth and income distribution, using simulation models which incorporate intergenerational ability transmission and endogenous fertility. The simulation results show that financial support for higher education can both increase economic growth and reduce income inequality, especially if parent and child abilities are closely correlated. In contrast with educational subsidy, raising childcare or family allowance has limited impact on growth and income inequality. Furthermore, we find that educational subsidy affects economic growth and income distribution largely through its impact on the wage distribution rather than on the ability distribution.

Our analysis has many limitations. For instance, the results may be more or less modified if heterogeneous households with different preferences, an endogenous labor supply, or an old-age social security system is taken into account. Despite these caveats, this study highlights the importance of educational subsidy in terms of both efficiency 
and equity. If ability is strongly transmitted between generations and education requires high costs, there is the risk that education may sustain or even amplify income inequality in successive generations, due to limited opportunities for education among low-income individuals. Moreover, the substitution between child quality and child quantity may raise the proportion of low-educated workers and depress per capita GDP and economic growth. Financial support for education is expected to mitigate these adverse effects of education on the economy and social welfare.

$<<$ Insert Appendix table about here. $>>$ 


\section{References}

Becker GS (1967) Human Capital and the Personal Distribution of Income.

Woytinski Lecture No. 1. University of Michigan Press, Ann Arbor.

Becker GS, Tomes N (1976) Child Endowments and the Quantity and Quality of Children. Journal of Political Economy 84(4):S143-S162.

Becker GS, Tomes N (1979) An Equilibrium Theory of the Distribution of Income and Intergenerational Mobility. Journal of Political Economy 87(6): 1153-1189.

de la Croix D, Doepke M (2003) Inequality and Growth: Why Differential Fertility Matters. American Economic Review 93(4):1091-1113.

Fender J, Wang P (2003) Educational Policy in a Credit Constrained Economy with Skill Heterogeneity. International Economic Review 44(3):939-964.

Galor O, Zang H (1997) Fertility, Income Distribution, and Economic Growth: Theory and Cross-country Evidence. Japan and the World Economy 9(2):197-229.

Glomm G, Ravikumar B (1992) Public vs. Private Investment in Human Capital: Endogenous Growth and Income Inequality. Journal of Political Economy 100(4):818-834.

Han S, Mulligan CB (2001) Human Capital, Heterogeneity and Estimated Degrees of Intergenerational Mobility. Economic Journal 111(470):207-43.

Hanushek, EA (1992) The Trade-off between Child Quantity and Quality. Journal of Political Economy 100(1):84-117.

Hanushek EA, Leung CKY, Yilmaz K (2003) Redistribution through Education and Other Transfer Mechanisms. Journal of Monetary Economics 50(8):1719-1750.

Hanushek EA, Leung CKY, Yilmaz K (2004) Borrowing Constraints, College Aid, and Intergenerational Mobility. NBER Working Paper 10711.

Iyigun MF (1999) Public Education and Intergenerational Economic Mobility. 
International Economic Review 40(3):697-710.

Kremer M, Chen D (2002) Income-distribution Dynamics with Endogenous Fertility. Journal of Economic Growth 7(3):227-58.

Maoz YD, Moav O (1999) Intergenerational Mobility and the Process of Development. The Economic Journal 109(458):677-697. 
Table 1. Assumed policy parameters and calculated wage tax rates

\begin{tabular}{|c|c|c|c|c|}
\hline & Baseline & Educational subsidy & Childcare allowance & Family allowance \\
\hline \multicolumn{5}{|c|}{ Case 1: $\left(\sigma_{1}, \sigma_{2}, \sigma_{3}\right)=(0,1,0)$} \\
\hline$\theta$ & 0 & 0.5 & 0 & 0 \\
\hline$\delta_{1}$ & 0.0225 & 0.0225 & 0.0225 & 0.0225 \\
\hline$\delta_{5}$ & 0.0225 & 0.0225 & 0.0330 & 0.0225 \\
\hline$\delta_{10}$ & 0.0225 & 0.0225 & 0.0328 & 0.0225 \\
\hline$m_{1}$ & 0.2 & 0.2 & 0.2 & 0.2 \\
\hline$m_{5}$ & 0.2 & 0.2 & 0.2 & 0.2099 \\
\hline$m_{10}$ & 0.2 & 0.2 & 0.2 & 0.2097 \\
\hline$\tau_{1}$ & 0.2408 & 0.2408 & 0.2408 & 0.2408 \\
\hline$\tau_{5}$ & 0.2406 & 0.2506 & 0.2506 & 0.2506 \\
\hline$\tau_{10}$ & 0.2407 & 0.2506 & 0.2506 & 0.2506 \\
\hline \multicolumn{5}{|c|}{ Case 2: $\left(\sigma_{1}, \sigma_{2}, \sigma_{3}\right)=(0.125,0.75,0.1)$} \\
\hline$\theta$ & 0 & 0.5 & 0 & 0 \\
\hline$\delta_{1}$ & 0.0225 & 0.0225 & 0.0225 & 0.0225 \\
\hline$\delta_{5}$ & 0.0225 & 0.0225 & 0.0338 & 0.0225 \\
\hline$\delta_{10}$ & 0.0225 & 0.0225 & 0.0337 & 0.0225 \\
\hline$m_{1}$ & 0.2 & 0.2 & 0.2 & 0.2 \\
\hline$m_{5}$ & 0.2 & 0.2 & 0.2 & 0.2106 \\
\hline$m_{10}$ & 0.2 & 0.2 & 0.2 & 0.2105 \\
\hline$\tau_{1}$ & 0.2408 & 0.2408 & 0.2408 & 0.2408 \\
\hline$\tau_{5}$ & 0.2405 & 0.2513 & 0.2513 & 0.2513 \\
\hline$\tau_{10}$ & 0.2405 & 0.2513 & 0.2513 & 0.2513 \\
\hline \multicolumn{5}{|c|}{ Case 3: $\left(\sigma_{1}, \sigma_{2}, \sigma_{3}\right)=(0.25,0.5,0.1)$} \\
\hline$\theta$ & 0 & 0.5 & 0 & 0 \\
\hline$\delta_{1}$ & 0.0225 & 0.0225 & 0.0225 & 0.0225 \\
\hline$\delta_{5}$ & 0.0225 & 0.0225 & 0.0346 & 0.0225 \\
\hline$\delta_{10}$ & 0.0225 & 0.0225 & 0.0346 & 0.0225 \\
\hline$m_{1}$ & 0.2 & 0.2 & 0.2 & 0.2 \\
\hline$m_{5}$ & 0.2 & 0.2 & 0.2 & 0.2113 \\
\hline$m_{10}$ & 0.2 & 0.2 & 0.2 & 0.2113 \\
\hline$\tau_{1}$ & 0.2408 & 0.2408 & 0.2408 & 0.2408 \\
\hline$\tau_{5}$ & 0.2405 & 0.2520 & 0.2520 & 0.2520 \\
\hline$\tau_{10}$ & 0.2404 & 0.2520 & 0.2520 & 0.2520 \\
\hline
\end{tabular}


Figure 1. Distribution of individual ability: simulation results
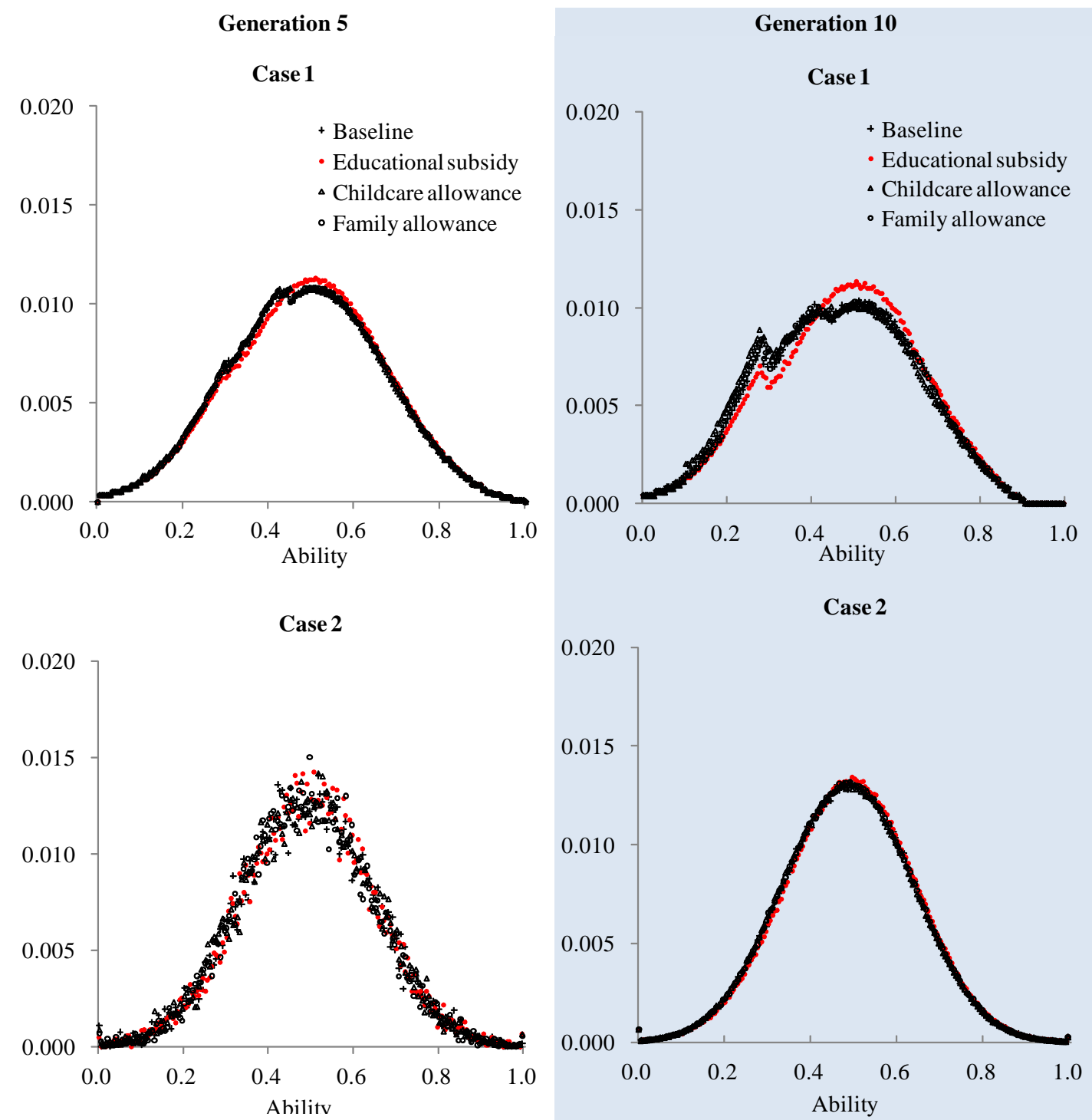

Case 3

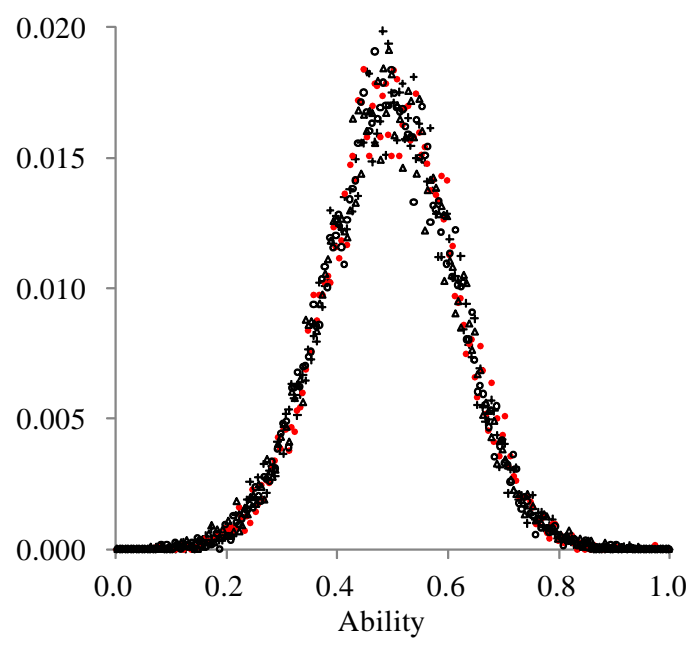

Case 3

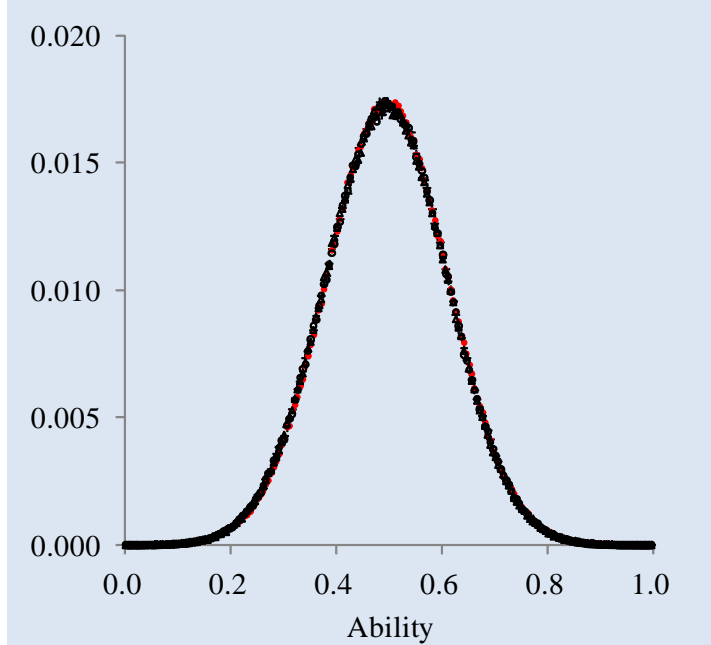


Figure 2. Proportions of low-wage individuals: simulation results

Generation 5

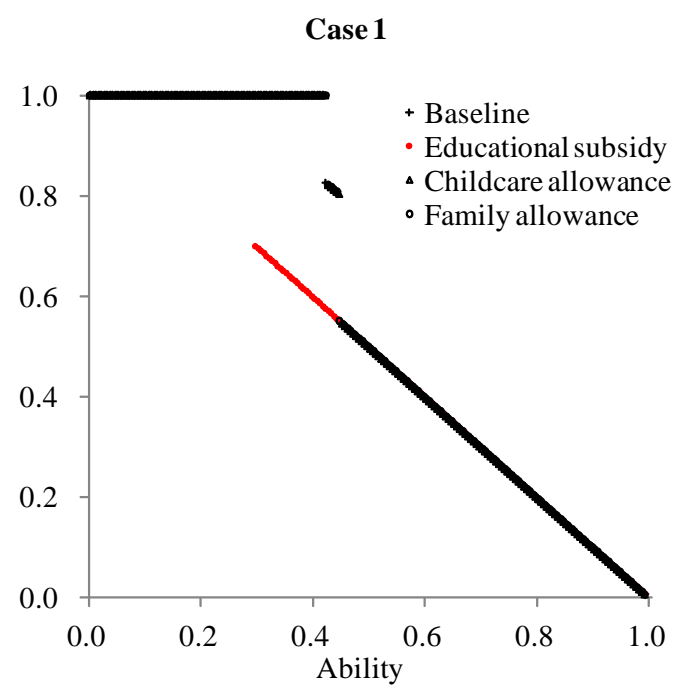

Case 2

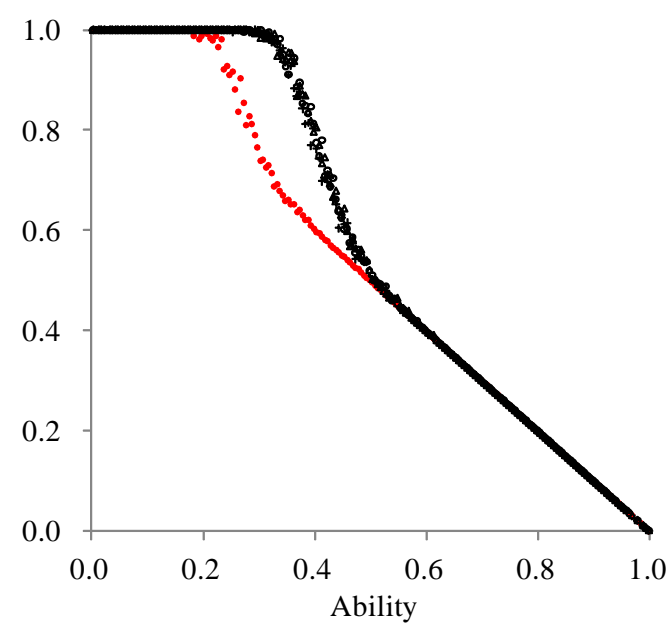

Case 3

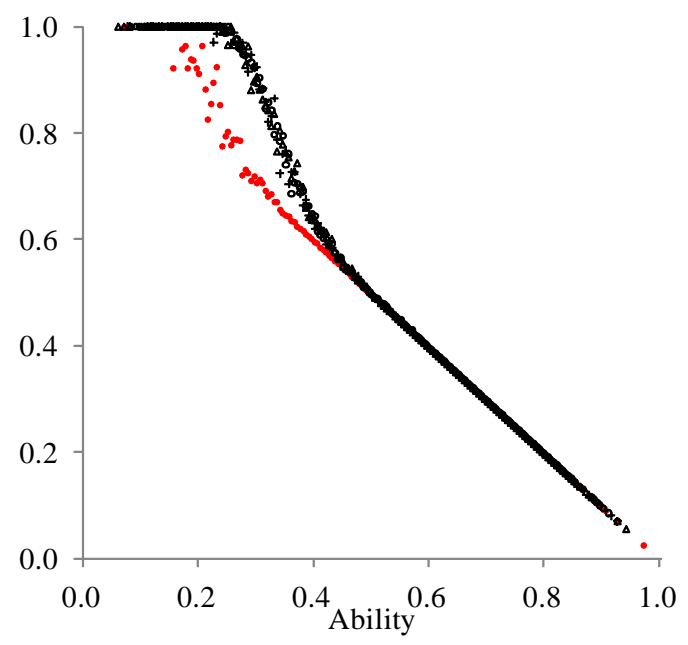

Generation 10

Case 1

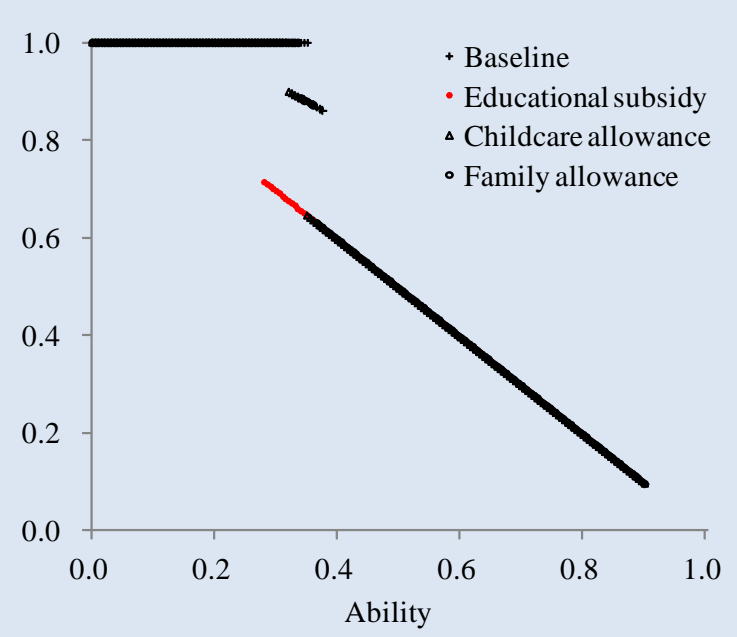

Case 2

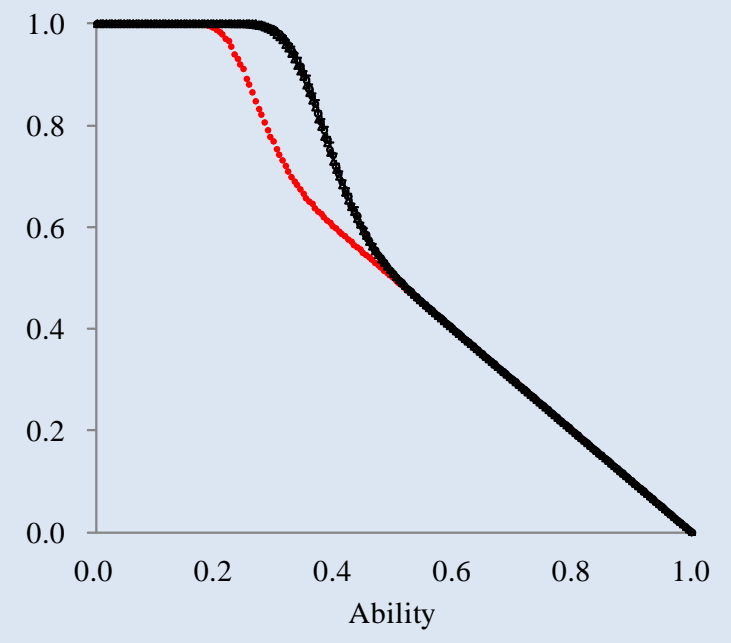

Case 3

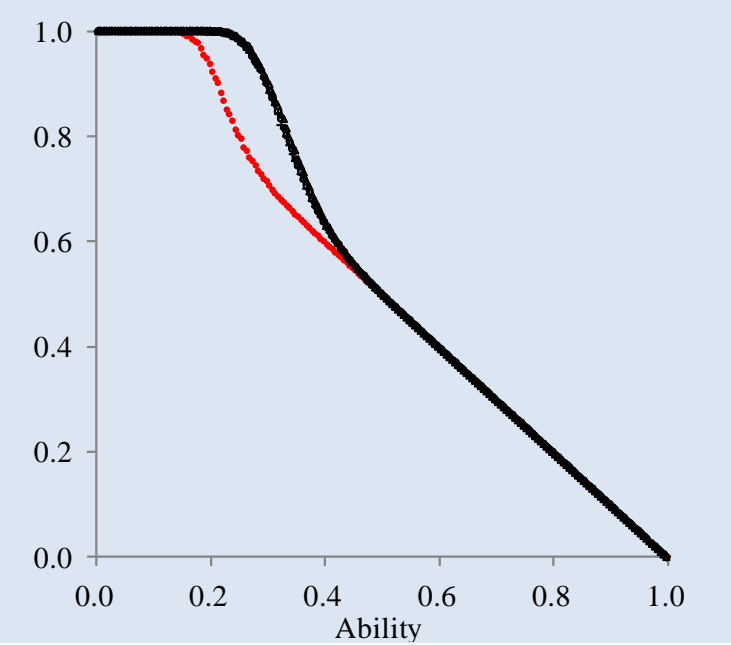


Table 2. Total population, per capita GDP, and the Gini coefficient: simulation results

\begin{tabular}{|c|c|c|c|c|c|c|c|c|}
\hline \multirow{2}{*}{\multicolumn{2}{|c|}{$\begin{array}{cr}\text { Case } & \text { Generation } \\
\text { Total population }(\text { Generation } 1=100)\end{array}$}} & \multirow[t]{2}{*}{ Baseline } & \multicolumn{2}{|c|}{ Educational subsidy } & \multicolumn{2}{|c|}{ Childcare allowance } & \multicolumn{2}{|c|}{ Family allowance } \\
\hline & & & & & & & & \\
\hline \multirow[t]{3}{*}{ Case 1} & 1 & 100.0 & 100.0 & & 100.0 & & 100.0 & \\
\hline & 5 & 85.9 & 89.2 & $(3.8)$ & 92.5 & (7.6) & 88.6 & (3.1) \\
\hline & 10 & 69.0 & 77.7 & $(12.6)$ & 84.1 & $(21.8)$ & 74.8 & (8.3) \\
\hline \multirow[t]{3}{*}{ Case 2} & 1 & 100.0 & 100.0 & & 100.0 & & 100.0 & \\
\hline & 5 & 84.4 & 88.4 & $(4.7)$ & 91.3 & $(8.2)$ & 87.3 & (3.4) \\
\hline & 10 & 65.6 & 75.8 & $(15.5)$ & 81.4 & $(24.0)$ & 71.9 & (9.6) \\
\hline \multirow[t]{3}{*}{ Case 3} & 1 & 100.0 & 100.0 & & 100.0 & & 100.0 & \\
\hline & 5 & 82.4 & 87.8 & $(6.6)$ & 89.6 & (8.7) & 85.4 & (3.7) \\
\hline & 10 & 62.8 & 75.0 & (19.5) & 78.9 & $(25.6)$ & 69.4 & $(10.5)$ \\
\hline \multicolumn{9}{|c|}{ Per capita GDP (Generation $1=100)$} \\
\hline \multirow[t]{3}{*}{ Case 1} & 1 & 100.0 & 100.0 & & 100.0 & & 100.0 & \\
\hline & 5 & 96.9 & 99.2 & (2.3) & 95.9 & $(-1.1)$ & 96.6 & $(-0.3)$ \\
\hline & 10 & 95.0 & 97.2 & $(2.2)$ & 92.8 & $(-2.4)$ & 94.4 & $(-0.6)$ \\
\hline \multirow[t]{3}{*}{ Case 2} & 1 & 100.0 & 100.0 & & 100.0 & & 100.0 & \\
\hline & 5 & 98.2 & 99.9 & $(1.7)$ & 97.6 & $(-0.6)$ & 97.9 & $(-0.3)$ \\
\hline & 10 & 98.8 & 99.7 & $(0.9)$ & 98.2 & $(-0.5)$ & 98.6 & $(-0.2)$ \\
\hline \multirow[t]{3}{*}{ Case 3} & 1 & 100.0 & 100.0 & & 100.0 & & 100.0 & \\
\hline & 5 & 99.7 & 100.4 & $(0.7)$ & 99.5 & $(-0.2)$ & 99.6 & $(-0.1)$ \\
\hline & 10 & 99.7 & 100.4 & $(0.6)$ & 99.6 & $(-0.1)$ & 99.7 & $(-0.0)$ \\
\hline \multicolumn{9}{|l|}{ Gini coefficient } \\
\hline \multirow[t]{3}{*}{ Case 1} & 1 & 0.1524 & 0.1524 & & 0.1524 & & 0.1524 & \\
\hline & 5 & 0.1583 & 0.1531 & $(-3.3)$ & 0.1590 & $(0.4)$ & 0.1565 & $(-1.1)$ \\
\hline & 10 & 0.1636 & 0.1555 & $(-4.9)$ & 0.1652 & (1.0) & 0.1629 & $(-0.4)$ \\
\hline \multirow[t]{3}{*}{ Case 2} & 1 & 0.1524 & 0.1524 & & 0.1524 & & 0.1524 & \\
\hline & 5 & 0.1375 & 0.1324 & $(-3.7)$ & 0.1363 & $(-0.9)$ & 0.1360 & $(-1.1)$ \\
\hline & 10 & 0.1335 & 0.1306 & $(-2.2)$ & 0.1324 & $(-0.8)$ & 0.1317 & $(-1.4)$ \\
\hline \multirow[t]{3}{*}{ Case 3} & 1 & 0.1524 & 0.1524 & & 0.1524 & & 0.1524 & \\
\hline & 5 & 0.1048 & 0.1017 & $(-2.9)$ & 0.1031 & $(-1.6)$ & 0.1029 & $(-1.8)$ \\
\hline & 10 & 0.1038 & 0.1014 & $(-2.2)$ & 0.1020 & $(-1.7)$ & 0.1017 & $(-2.0)$ \\
\hline
\end{tabular}

Note: The figures in the parentheses indicate percentage differences from the baseline in each generation. 


\section{Appendix table. Assumed parameter values}

\begin{tabular}{llr}
\hline Opportunity cost of childrearing/average after-tax income $^{\mathrm{a}}$ & $\zeta$ & 0.5 \\
Childcare allowance/average after-tax income $^{\mathrm{b}}$ & $\delta$ & 0.0225 \\
Family allowance/average before-tax income $^{\mathrm{c}}$ & $m$ & 0.2 \\
Basic cost of childrearing/average after-tax income $^{\mathrm{d}}$ & $\xi$ & 0.75 \\
Cost of low education/average after-tax income $^{\mathrm{d}}$ & $e^{L}$ & 0.05 \\
Cost of high education/average after-tax income $^{\mathrm{d}}$ & $e^{H}$ & 0.075 \\
Weight on high-wage workers in production $^{\mathrm{e}}$ & $\varepsilon$ & 0.55 \\
Government consumption/GDP $^{\mathrm{f}}$ & $c$ & 0.02 \\
Elasticity of substitution in production $^{\mathrm{g}}$ & $\rho$ & 0.5 \\
Aggregate productivity $^{\mathrm{h}}$ & $k$ & 1 \\
Production parameter $^{\mathrm{h}}$ & $A$ & 1 \\
Utility weight on child's wage $^{\mathrm{h}}$ & $\alpha$ & $1 / 3$ \\
Utility weight on the number of children $^{\mathrm{h}}$ & $\beta$ & $1 / 3$ \\
Utility weight on own consumption $^{\mathrm{h}}$ & $\gamma$ & $1 / 3$ \\
\hline
\end{tabular}

Note:

a. White Paper on National Lifestyle 2005 (Cabinet Office, 2005) estimated the opportunity cost of childrearing to be $21.3 \%-82.2 \%$ of women's lifetime income in Japan. We use $50 \%$, close to their average, as the ratio of cost of childrearing to lifetime income.

b. Useful Labor Statistics 2010 (The Japan Institute for Labor Policy and Training, 2010) estimated lifetime income to be 150-300 million yen in Japan, depending on educational attainment. On that basis, we assume that average lifetime income is 200 million yen. Meanwhile, the Japanese government is now introducing a child allowance of 2.8 thousand yen per child in total (until 18 years old) and plans to expand it to 5.6 thousand yen. We assume the child allowance to be 4.5 thousand yen, close to the average and equivalent to $2.25 \%$ of the assumed lifetime income.

c. The welfare assistance benefit per adult is equal to 840-960 thousand yen a year under the current law in Japan. On this basis, we assume that family allowance is one million yen, roughly equal to $20 \%$ of the assumed annual income of 5 million yen (= 200 million yen / 40 years).

d. The Modern Economics of Childrearing (American International Underwriters Corporation, 2005) estimated the average cost of childrearing (excluding the opportunity cost), the education cost up to high school and that up to national university to be 16.40, 9.53, and 13.45 million yen, respectively, in Japan. We assume these to be 15,10 , and 15 million yen, respectively, which are equivalent to $7.5 \%, 5 \%$, and $7.5 \%$ of the assumed lifetime income.

e. Useful Labor Statistics 2010 estimated the average lifetime income for high school (or below) graduates and college (or above) graduates are 220-260 and 300 million yen, respectively, in Japan. Hence, we assume their wage ratio to be $1.25(=300 /[(220+260) / 2])$, which roughly corresponds to $\varepsilon$ $=0.55(\approx 1.25 /(1+1.25))$.

f. National Accounts 2008 (Cabinet Office, 2010) showed that the government expenditure on services excluding education and medical care was 7.2 trillion in Japan. We assume it to be 10 trillion, roughly equivalent to $2 \%$ of GDP.

g. Based on Hanushek et al. (2004).

h. Tentatively assumed. 